\title{
O Ecoturismo no Cerrado: reflexões e oportunidades na RPPN Santuário do Caraça (MG)
}

\author{
Ecotourism in "Cerrado" (Brazilian Savannah): reflections and opportunities \\ in RPPN Caraça Sanctuary (MG, Brazil)
}

\section{Isabela Barbosa Frederico, Heloísa Turini Bruhns}

\begin{abstract}
RESUMO
O presente artigo faz parte de uma pesquisa de mestrado, em desenvolvimento, do Departamento de Geografia da Universidade Estadual de Campinas, e tem como objetivo explorar uma iniciativa, em específico, de ecoturismo em ambientes de cerrado. Este bioma nacional, segundo em área territorial, resguarda importantes organismos de flora e fauna do país, muitos de caráter endêmico. Apesar de sua importância, encontra-se esquecido no imaginário da população e também em iniciativas de conservação, caracterizando-se como um hotspot, sofrendo impactos negativos derivados do avanço agropecuário. Esta savana, considerada a mais biodiversa do mundo, necessita de iniciativas de preservação que sensibilizem o ser humano a respeito de sua importância e situação de perigo atual. Nesse contexto, o ecoturismo emerge como uma possibilidade de reaproximação do homem com a natureza através da experiência e subjetividade, possibilitando situações de aprendizado informal e lúdico do ambiente. A busca pela natureza hoje, enquanto fenômeno social contemporâneo deve ultrapassar a dicotomia entre cultura e natureza apontando novas possibilidades de ação e conservação. É um consenso nos debates ambientais a importância da mudança de percepção que contemple não apenas o olhar racional do espaço, mas também a dimensão emotiva do ser humano. Desta forma, este estudo enfoca em um caso, em específico, de ecoturismo em áreas de cerrado, que é o da RPPN "Santuário do Caraça", localizada no estado de Minas Gerais. Esta unidade possibilita a análise de situações interessantes em relação a esta atividade sendo elas a iniciativa de conservação em uma área particular, de posse de uma organização religiosa; o ecoturismo como alternativa para a preservação do ambiente e de um patrimônio histórico presente além da existência de um ritual que ocorre entre os padres da reserva e uma espécie endêmica do bioma, o lobo guará. Os resultados apresentados constituem em uma revisão bibliográfica sobre o tema e a relação desta com discursos dos visitantes, fruto da primeira fase da pesquisa. Estes discursos, de caráter qualitativo, foram coletados através de entrevistas semiestruturadas no período de julho de 2011, mês de alta recepção de turistas na unidade. Através destes foi possível observar a existência de um imaginário de valorização de grandes florestas em detrimento de paisagens inerentes ao cerrado. Porém, que o contato com este ambiente, através de dimensões mais emotivas do ser humano, provoca uma sensibilização e reflexão acerca dos impactos negativos gerados à natureza pela sociedade contemporânea, além de evidenciar um desejo de cuidado pelo ambiente após a experiência de contato com o local. $\mathrm{O}$ Ritual do Lobo Guará incita a curiosidade e o olhar mais subjetivo em relação ao local visitado. Entretanto, estas são as primeiras análises realizadas na unidade, o que evidencia o seu caráter peculiar no universo das iniciativas de ecoturismo neste bioma, revelando a importância do desenvolvimento da pesquisa na mesma.
\end{abstract}

PLAVRAS-CHAVE: Cerrado; Ecoturismo; Percepção Ambiental.

Página 600 Revista Brasileira de Ecoturismo, São Paulo, v.5, n.3, set/dez 20I2, Pp.600-6I5.

Sociedade Brasileira de Ecoturismo. Rua Dona Ana, 138, Vila Mariana, São Paulo, SP - Brasil. E-mail: rbecotur@sbecotur.org.br; Tel. (55-II) 99196-7685 


\begin{abstract}
This article is part of a research in development, from the Department of Geography at University of Campinas, and aims to explore an initiative, in particular, ecotourism in cerrado environments. This national biome, second in land area, protects important bodies of flora and fauna of the country, many of endemicity. Despite its importance, is forgotten in the minds of the population and also in conservation initiatives, characterized as a hotspot, suffering negative impacts derived from agricultural advancement. This savanna, considered the most biodiverse in the world, requires preservation initiatives which raise awareness about the human being of their importance and danger present. In this context, ecotourism has emerged as a possible rapprochement between man and nature through experience and subjectivity, enabling informal learning situations and playful environment. The search for nature today as a contemporary social phenomenon must overcome the dichotomy between nature and culture offering new possibilities for action and conservation. It is a consensus in the discussions the importance of environmental change in perception that it's not only the look of the rational space, but also the emotional dimension of being human. Thus, this study focuses on a specific case in ecotourism in areas of "Cerrado" (Brazilian Savannah), which is the RPPN "Santuário do Caraça", located in the state of Minas Gerais. This unit enables the analysis of interesting situations in relation to this activity it is a conservation initiative in a particular area, in possession of a religious organization; ecotourism as an alternative to preserving the environment and heritage of this than the existence of a rites that takes place between priests of booking and an endemic specie of the biome, the Guará wolf. The results are presented in a literature review on the subject and its relation to discourses of visitors, the result of the first phase of the research. These discourses, qualitative, were collected through semi-structured in the period from July 2011, the month in which the number of tourists is high. Through these it was possible to observe the existence of an imaginary large valuation at the expense of forests landscapes inherent in the cerrado. However, that the contact with this environment, through emotive dimensions of the human being, causes an awareness and reflection about the negative impacts generated to the nature by contemporary society, in addition to demonstrating a desire to care for the environment after the experience of contact with the site. The Ritual of Lobo Guará encourages curiosity and the subjective look in relation to the place visited. However, these are the first analyses carried out in the unit, which highlights its peculiar character in the universe of ecotourism initiatives in this biome, revealing the importance of research development in it.
\end{abstract}

KEYWORDS: Cerrado; Ecotourism; Environmental Perception.

\title{
Introdução
}

A questão ambiental, em conjunto com os movimentos contraculturais começaram a iluminar as grandes discussões sobre a proteção do planeta e formas de vida a partir da década de 60. Com o estopim de obras como "Walden ou a vida nos bosques" de Thoreau (com a primeira publicação no ano de 1854, porém com grande influência nas ideias ambientalistas do período) e "A Primavera Silenciosa" de Raquel Carson (no ano de 1962), o mundo experimentou um embate em relação aos padrões de crescimento e dominação até então vivenciados pela humanidade. 
Nesse ínterim diversos setores da sociedade começaram a dialogar sobre suas posições em relação à problemática ambiental e assim consequentemente apresentaram possíveis soluções para o desequilíbrio enfrentado. No campo das ciências, surge a necessidade de se quebrar a visão racionalista assim como a posição romântica em relação à natureza. Faria (2002) nos recorda que a partir do século XIX, o interesse das grandes ciências na relação das ações sociais sobre o espaço se deu pela orientação de um modelo de crescimento com duas facetas: de um lado os recursos naturais que deviam ser utilizados pelos agentes sociais hegemônicos em larga escala, e do outro, um conceito de natureza dotada de equilíbrio, harmonia e naturalidade se opondo às esferas da sociedade ganhando o status de natureza intocada.

Essas duas vertentes contrastantes mantiveram a dualidade entre o homem e a natureza, num entendimento onde ambos constituem-se de instituições separadas e distintas. No entanto, com o avanço do debate em torno da questão ambiental, principalmente com os eventos mundiais sobre o tema, esse pensamento dualista foi se rompendo e dando lugar a outras dimensões interagindo homem e natureza. A conferência Rio 92, por exemplo, teve como grande marco o diálogo entre várias culturas e setores da sociedade mundial que lograram discutir a problemática socioambiental por vieses que ultrapassavam os marcos tradicionalistas do mercado e da política, como exemplo a espiritualidade (LEIS, 1998).

Atualmente diversos campos das ciências dialogam juntos sobre a questão ambiental estabelecendo um campo reintegrador de saberes. No caso da geografia, vários estudos contribuem para o entendimento entre o homem e seu ambiente. Guimarães (2002) nos informa que os estudos geográficos têm, em diferentes períodos, buscado compreender a tradução das experiências ambientais sob as variáveis de ordem natural, social e/ou cultural.

Esses estudos apontam o Brasil entre os países com maiores índices de biodiversidade mundial, o que aumenta a sua responsabilidade na preservação do meio ambiente. Dentro desse cenário biodiverso encontra-se o cerrado, um bioma com alto grau de endemismo e uma presença de diversas fisionomias/paisagens em sua abrangência territorial. Apesar de ser apontado como a savana tropical mais rica do mundo, este bioma encontra-se muito pouco protegido legalmente e muitas vezes menosprezado no imaginário brasileiro (KLINK; MACHADO, 2005).

Neiman e Rabinovici (2002) ao abordarem o bioma sob a perspectiva do ecoturismo e da educação ambiental, apontam controvérsias como, a fisionomia da paisagem insinuando aos visitantes uma escassez de água, o que na verdade não ocorre. Porém essa ideia de "escassez" permanece na concepção dos sujeitos. Assim, o cerrado pode ser desmerecido em relação a cenários que abriguem, por exemplo, grandes florestas e cachoeiras. Bruhns (2010) destaca como o ecoturismo privilegia áreas naturais apelativas do ponto estético, levando em conta os valores ocidentais.

Este bioma apesar de desprezado tanto em termos de valorização estética como em legislação conservacionista, merece um olhar atento às suas belezas, particularidades e importância. Schama (1995, p.24) nos coloca em sua obra a necessidade que temos de "um modo de olhar, de redescobrir o que já possuímos, mas que de alguma forma nos escapa ao reconhecimento e à apreciação". O objetivo do autor não é resgatar um cená- 
rio perdido, mas revelar o que ainda podemos encontrar e valorizar.

Mamede e Benites (2008) afirmam que a transformação dos olhares sobre o cerrado exige uma necessidade de reorientação e vivência com o bioma. Nessa transformação, segundo as autoras, os sentimentos e as emoções dos indivíduos devem ser explorados e estimulados. Assim sendo, o ecoturismo se mostra como uma oportunidade no sentido de se aliar o desejo de conhecer, de fazer parte e de contemplar esse bioma.

O ecoturismo pode ser destacado como ferramenta de possível intervenção no patrimônio natural através da dimensão subjetiva e experiencial do ser humano. A busca pela natureza hoje, como fenômeno social contemporâneo deve ultrapassar a dicotomia entre cultura e natureza apontando novas possibilidades de ação.

Para Tuan (1983) as experiências são constituídas de sentimento e pensamento, os quais estão estreitamente vinculados em um continuum experiencial, constituindo maneiras de se conhecer. Portanto a da experiência proporcionada pelo ecoturismo em áreas de cerrado estimula a imbricação entre razão e emoção, atribuindo valores a esse bioma.

É nesse contexto que as experiências no presente bioma devem ser estudadas e interpretadas. Irving (2008) atenta para a necessidade de enfocar o turista como um "agente de transformação", desvinculando-o do caráter de marionete de agências de ecoturismo e do mercado verde, tornando-se capaz de decidir e impor mudanças de processo. Para a autora está aqui provavelmente a essência do conceito de planejamento ecoturístico. Tuan (1983) também coloca a importância de se entender a rica informação derivada da experiência para os futuros processos de planejamento.

Sob este cenário emerge o interesse do presente artigo em compreender como se dá a relação entre homem e natureza em áreas de cerrado. Em um contexto mais amplo, este trabalho faz parte de uma pesquisa de mestrado que está sendo desenvolvida no Departamento de Geografia, do Instituto de Geociências da Universidade Estadual de Campinas.

Com o desejo de se compreender novas alternativas de desenvolvimento em um contexto de crise, como o atual, a investigação em questão busca explorar um caso que ocorre em uma Reserva Particular do Patrimônio Natural chamada "Santuário do Caraça".

Essa opção se sustenta em função da mesma apresentar visitação turística durante todo o ano, com maior intensidade nos meses de janeiro, fevereiro e julho, mas principalmente por esta área possibilitar a análise de três situações interessantes envolvendo a questão ambiental: a iniciativa de conservação em uma propriedade particular mantida desde 1819 pela Missão dos Lazaristas; o ecoturismo como alternativa para a preservação, e a relação entre a cultura e o meio ambiente. Esta relação se dá através da presença de um patrimônio histórico local e uma tradição que se tornou ícone da reserva, qual seja, o ritual da alimentação aos lobos guarás (espécie de mamífero endêmica do cerrado) que ocorre diariamente após o jantar na escadaria da igreja localizada na área.

Os resultados que serão apresentados constituem a primeira parte da pesquisa, na qual foram realizadas visitas exploratórias à reserva e aplicadas entrevistas semiestruturadas aos visitantes, como forma de caracterizar o cenário estudado e ressaltar as errâncias existentes no mesmo. Para isso, o artigo inicia com a retomada de uma contextuali- 
zação teórica sobre a situação do bioma cerrado no cenário nacional, após isso busca-se uma aproximação bibliográfica acerca das possibilidades que o ecoturismo apresenta enquanto reaproximação do homem ao seu meio, tendo em vista a experiência como abertura para as dimensões emotivas do ser humano, bem como a possibilidade de uma revisão de valores e posturas em relação a si próprio, à outredade e ao meio ambiente.

Em um segundo momento são trazidos alguns dos discursos coletados com os visitantes como forma de aclarar o contexto existente no "Santuário do Caraça" e abrir indagatórias acerca das alternativas encontradas nesta experiência de ecoturismo no bioma em questão, além do enfoque nas relações que ai se desdobram. Os relatos apresentados foram coletados através de entrevistas semiestruturadas realizadas durante a primeira visita exploratória à Reserva, no mês de julho de 2011.

\section{Desenvolvimento}

\section{O cerrado no contexto atual}

O cerrado é o segundo maior bioma brasileiro (representando cerca de $25 \%$ do território nacional) ficando atrás apenas da Floresta Amazônica. Localizado na região central do país, abrange 17 estados, com maior expressividade em Goiás, Tocantins e no Distrito Federal (GOODLAND; FERRI, 1979; MMA, 2007).

Considerado como a grande savana brasileira, este bioma abriga uma megadiversidade de flora e fauna de grande relevância, com um número considerável de espécies de caráter endêmico. Além disso, o cerrado apresenta alta porcentagem de representatividade de mamíferos $(37 \%)$, aves $(49 \%)$, répteis $(50 \%)$ e peixes $(40 \%)$ em relação à totalidade de espécies no Brasil (KLINK; MACHADO, 2005).

Em relação à fisionomia vegetal, o cerrado abriga um verdadeiro mosaico com a presença de formações florestais; savânicas e campestres (MMA, 2007). Ao abordar a ecologia do bioma, Goodland; Ferri (1979) descrevem a paisagem deste como sendo uma mistura de árvores baixas e um estrato herbáceo rasteiro altamente desenvolvido.

No sentido horizontal, os ambientes de cerrado sofrem diversas mudanças, podendo conter em uma mesma região áreas campestres, capões de mata, florestas e áreas brejosas (MACHADO et. al., 2004)

Outra característica relevante é o fato deste abrigar as nascentes de importantes bacias hidrográficas da América do Sul como a Amazônica, a do São Francisco e a Platina (WWF - Brasil, 2000). A sua conservação torna-se necessária então para a manutenção da biodiversidade presente na Amazônia e no Pantanal, uma vez que acolhe as nascentes dos principais rios que banham esses biomas.

Apesar das evidências de sua importância, o cerrado vem sendo bastante ameaçado, caracterizando-se como um hotspot. Segundo Felfili et. al. (2005) restam apenas $20 \%$ da cobertura original do bioma. Esse número reflete a intensa pressão que as ameaças das pastagens para a criação de gado de corte e a monocultura (ex: a soja) estão impondo sobre o mesmo (MACHADO et. al., 2004).

Uma das alternativas encontradas para a conservação das áreas naturais no Brasil foi a criação das Unidades de Conservação. Em relação ao cerrado, estas áreas estão 
restritas em torno de $2 \%$ de toda sua extensão, um número inexpressivo em termos de preservação. Portanto, a relevância dessas unidades é colocada ao lado da necessidade de políticas públicas que contemplem a conservação e a educação ambiental, assim como um novo modelo de desenvolvimento mais crítico que incorpore outras dimensões além da econômica (RODRIGUES, 2005; MAMEDE; BENITES, 2008).

\section{O ecoturismo enquanto possibilidade de reaproximação}

A prática do ecoturismo tem-se revelado como forma de novas sensibilidades através da experiência. Algumas unidades de conservação permitem essa prática e para tanto, a atividade deve estar alinhada com os princípios éticos de preservação e educação, bem como com o plano de manejo ou de uso público. Apesar desse não ser o cenário sempre presenciado (por vários motivos como a ausência de infraestrutura, a existência do turismo de massa, entre outros) não podemos descartar o ecoturismo como uma possibilidade de integração entre homem e natureza, afastando-se dos extremismos e das concepções culturalistas (natureza como necessidade de ser domesticada) e naturalistas (natureza contendo todas as virtudes).

$\mathrm{Na}$ concepção culturalista a natureza ganha o status de algo inanimado e mecânico. Nesse sentido emerge um mundo que evita o sensível, valorizando uma descrição quantitativa da natureza e colocando a razão humana como centro do universo (GRUN, 1996). Carvalho (2001) nos coloca que nessa concepção a natureza é classificada segundo sua utilidade para as necessidades humanas, ou seja, o ideal de civilidade e cultura é construído em oposição à esfera do ambiente natural. Revela-se aqui o distanciamento entre homem e natureza, além da dualidade criada entre a razão e a emoção, entre o intelecto e a intuição, desvalorizando a experiência subjetiva.

Ao longo da década de 1970 o turismo de massa colaborou para a deterioração de alguns destinos (WESTERN, 2005). No ambiente natural, Diegues aponta distorções causadas pelo mito da "natureza intocada", o qual pode gerar conflitos pela desvalorização e o desrespeito com as comunidades tradicionais residentes (DIEGUES, 2004). Esse mito introduz um imaginário nos sujeitos sobre os "paraísos naturais", distanciando os mesmos e isentando-os de qualquer responsabilidade e estimulando a utilização desses espaços sob a ótica do consumo.

Ao refletir sobre a prática do turismo, mais especificadamente do ecoturismo (como forma de turismo alternativo que se contrapõe ao turismo de massa), Irving (2008) nos coloca a importância de evitarmos um olhar reducionista. Para a autora esta prática se caracteriza como um fenômeno social que ultrapassa as barreiras do mercado aproximando-se do cotidiano das pessoas, do modo como vivem, trabalham e se divertem. Enfim, da sua cultura e de seu universo simbólico.

Defendendo uma razão mais sensível, a qual deve incorporar elementos como o desejo, a imaginação, o afeto dentre outros, Bruhns (2007, p.63) demonstra a necessidade de desenvolvermos uma sensibilidade ecológica atenta "ao que a existência humana tem de enraizada, de sensível, de corporal, dando importância à dimensão emocional e afetuosa da estruturação social'.

Tuan (1983) afirma que a experiência consiste nas diversas formas (que podem 
ser as mais diretas e passivas como olfato, paladar e tato até a percepção visual e o simbolismo) pelas quais o indivíduo conhece e estrutura a realidade. Para o autor, a experiência, construto do pensamento e do sentimento, desemboca diretamente na capacidade de aprender através da vivência. Nesse sentido, o ecoturismo traz uma possibilidade do surgimento de novas relações e intervenções no meio ambiente, dotadas de sensibilidades.

Como expõe Tuan (1983) inicialmente um espaço indiferenciado possui forma abstrata, mas, a medida que o conhecemos e o dotamos de valor ele se transforma em lugar.

As experiências de ecoturismo no cerrado deparam-se com uma diversidade de paisagens e ecossistemas (MAMEDE; BENITES, 2008). Para as autoras o contato com o ambiente natural pode despertar a sensibilidade e alguns sentimentos como os de pertencimento à natureza. $\mathrm{O}$ mosaico de paisagens inerentes ao bioma proporciona as diversas formas de percepção, cientes que estas são frutos das relações do sujeito com sua sociedade, história e cultura. Como afirma Schama (1995, p.17) a paisagem "compõem-se tanto de camadas de lembranças quanto de estratos de rocha."

Nossa experiência corpórea é a mais direta e imediata, uma vez que constitui o primeiro referencial que temos com mundo (BRUHNS, 1997). Em se tratando de cerrado, o corpo entra em contato com um mosaico de paisagens que a princípio podem colidir com o imaginário baseado nas grandes florestas. Esse impacto vai sendo amenizado gradativamente pelo seu poder cênico (NEIMAN; RABINOVICI, 2002).

Como Tuan (1983) esclarece mais importante do que a duração da experiência está a qualidade e a intensidade que o contato pode gerar, sendo que está última varia de acordo com a emoção provocada ao longo do contato (NEIMAN; RABINOVICI, 2002).

As emoções e a sensibilização para as questões ambientais no ecoturismo podem ser impulsos desencadeados através da educação ambiental informal. Se resgatarmos o conceito de ecoturismo, essa educação compõe uma tríade com a preservação ambiental e o envolvimento das populações locais (PIRES, 1998). Para tanto, a EA deve renegar o viés estritamente informacional e descritivo, agregando uma composição onde o ser humano e a natureza relacionam-se num todo. Marin, Oliveira; Comar. (2005) revelam que a educação ambiental enriquece em reflexão e ação quando se abre para as dimensões não racionalistas do humano, o que não significa o descarte da racionalidade.

Para Carvalho (2003) o educar, dentro de uma perspectiva hermenêutica, constitui um trajeto onde o indivíduo e o mundo vivido vão se estabelecendo mutuamente em uma dialética de compreensão/ interpretação. Neste caso, a paisagem diversa do cerrado possibilita através da vivência e da interpretação um entendimento da complexidade e das simbologias que o envolve e the conferem significado e valor.

Compreensão esta possível uma vez que a paisagem é portadora de uma identidade, assim como a mediadora das relações entre o ser humano e a natureza, na qual elementos naturais e construídos por um viés simbólico exprimem uma ideia, uma concepção de vida, de sociedade e até mesmo de mundo (GUIMARÃES, 2002).

Para Cascino (2000) a retomada de uma educação ambiental ousada, crítica e transformadora contribui na reflexão sobre os espaços naturais e permite o ensejo do conhecer e experimentar para conservar. Nessa direção, as vivências íntimas do corpo com 
a natureza buscam o reconhecimento do espaço ocupado por esse corpo na sua relação com o mundo, "uma revisão de valores bem como um encontro muito particular do homem com ele mesmo" (BRUHNS, 1997, p.136).

O ecoturismo e a educação ambiental formam interessante parceria para o conhecimento sensível do ambiente natural, onde o elemento afetivo é fundamental. No caso de nossa savana, o cerrado, essa relação íntima envolvendo razão e emoção torna-se fundamental para sua conservação. Dentro do universo do ecoturismo, Mamede e Benites (2008) ressaltam as possibilidades temáticas inerentes ao cerrado, tais como: o percurso das águas, a flora, a cultura, a aventura e a contemplação, inserindo-o em um contexto mais amplo e profundo.

As vivências de ecoturismo desenvolvidas em unidades de conservação podem também contribuir para a quebra de preconceitos existentes na associação de programas de conservação e desenvolvimento (IRVING, 2008). Isto é, a ideia de que áreas de natureza preservada constituem um empecilho para o desenvolvimento econômico podem ser ultrapassadas uma vez que essa modalidade de turismo permite o uso equilibrado dos recursos naturais e o ganho econômico e social para as comunidades envolvidas.

\section{As experiências na RPPN "Santuário do Caraça"}

A Reserva Particular de Patrimônio Natural "Santuário do Caraça" está localizada no estado de Minas Gerais, nos municípios de Catas Altas e Santa Bárbara, a 120 km da capital do estado Belo Horizonte.

Está inserida no Quadrilátero Ferrífero, no começo da Serra do Espinhaço. Possui uma área de 11.200 hectares com áreas de transição entre a Mata Atlântica e o Cerrado. Goodland e Ferri (1979) nos colocam que apesar da grande maioria dos estados brasileiros terem este bioma (cerrado) em seus territórios, apenas Minas Gerais, Mato Grosso e Goiás possuem todas as variações que compõem essa vegetação.

A unidade está sob responsabilidade da Província Brasileira Congregação da Missão e se caracteriza por resguardar, além de riquezas naturais, um importante patrimônio histórico, como a primeira Igreja Neogótica do Brasil (1876), duas capelas barrocas no interior da igreja, uma capela restaurada localizada em uma das montanhas, imagens e peças sacras, a obra do Mestre Ataíde "Santa Ceia", além de construções no estilo colonial e gótico, claustros, catacumbas, um museu e uma biblioteca com cerca de 20 mil obras (PEREIRA; CARRIERI, 2005).

Inicialmente concebida como um colégio de padres, a Reserva do Caraça teve em seu âmago a religiosidade como norte de suas atividades. Após um incêndio acidental, este espaço se reconstruiu e hoje além de um recanto de espiritualidade também se configura como um cenário de turismo alternativo. Cabe aclarar, entretanto, que a priori esse turismo não foi planejado, porém como ressalta Pereira e Carrieri (2007) com a reconstituição do patrimônio histórico e religioso do Caraça, deu-se início a um turismo mais qualitativo em relação aos ideais e princípios do local. Atualmente, o antigo colégio funciona como uma pousada que recebe segundo a Coordenação Ambiental, uma média de 17.500 hóspedes por ano, já em termos de visitação a reserva recepciona cerca de 60.000 anuais.

O principal foco desse turismo reside em um ritual entre os padres e o lobo guará, 
animal endêmico do cerrado. Este contato, entre o animal e os padres da reserva, se deu inicialmente no ano de 1982, quando fora percebido que os lixões da reserva estavam sendo revirados pela noite. A partir desse acontecimento, o Padre Tobias, que coordenava a área, observou que se tratava da visita do lobo guará (Chrysocyon brachyurus). Desde então, os padres começaram a colocar bandejas com carne para o animal nos portões e logo foram subindo até chegar ao adro da igreja. Após três décadas esse ato continua vivo, constituindo-se como o grande atrativo da área.

Segundo a etnóloga Martine Segalen (2002, p.32) os ritos podem ser definidos como: "(...) um conjunto de condutas individuais ou coletivas, com suporte corporal (verbal, gestual e de postura), caráter repetitivo e forte carga simbólico para e testemunhas para autores e testemunhas." Além disso, a autora também agrega ao colocar que o rito, para sua existência, precisa basear-se em códigos simbólicos reconhecidos pela coletividade.

Nesse contexto, o rito do lobo guará, se configura em um tempo e em símbolos compartilhados pelas tradições religiosas presentes na reserva. $O$ momento de espera pelo animal traz características provenientes dessas crenças como o silêncio, o respeito, o ato de escutar o que o padre tem a falar, além de ser realizado momentos antes da celebração da missa noturna.

O Ritual do Lobo Guará se configura como um singular momento do turismo na reserva ao possibilitar o contato aproximado entre os visitantes e um importante representante da fauna do cerrado. Diferente das iniciativas comumente vistas, onde o turista sai e através de trilhas busca observar os animais existentes, nesse Ritual tem-se o fato da espera na igreja para que o lobo se aproxime das pessoas. Nesse momento de espera, realizado no período do entardecer, começo da noite, as pessoas são orientadas pelos padres a ficarem em silêncio oferecendo assim um clima de segurança para a aproximação do animal.

Em relação aos ritos de silêncio Bruhns e Marinho (2012) ressaltam a importância de se explorar esse momento, pois o mesmo facilita uma conexão com o ambiente a partir de sensibilidades como os sons do ambiente natural, muitas vezes distanciado do homem ao longo do cotidiano urbano. Além disso, as autoras ressaltam a dificuldade que o homem tem perante o ato do silêncio, muitas vezes renegando-o a categorias de "vazio", como falta ou ausência de algo.

Outro ponto importante dessa experiência com o lobo é o período na qual ela se dá: o início da noite. A reunião das pessoas ao redor do adro da igreja pela espera do animal se dá em um momento onde muitos deles já realizaram caminhadas, atividades de contemplação, informativas, entre outras, culminando em um momento onde já há uma reflexão acerca das vivências de todo o dia.

Em uma das falas coletadas ao longo da visita exploratória, pode-se comprovar como esse ritual se mostra intenso ao possibilitar reflexões mais profundas do visitante em relação aos seus hábitos e a preservação da área, assim como a relevância da conservação desta espécie.

Além disso, esse momento íntimo do visitante com o animal esclarece diversos paradigmas vigentes em uma sociedade urbanizada como a de que um animal selvagem sempre oferecerá perigo. 
O que mais me chama atenção, a proximidade que o lobo tem com as pessoas, a gente pensa que o lobo é animal selvagem não se aproxima das pessoas, aqui ele fica bem com as pessoas, e é interessante você tem a experiência de ficar próxima do lobo, normalmente a gente pensa ahh lobo, animal selvagem, ele vai me machucar, vai me comer, não sei o que as pessoas pensam, mas é uma experiência diferente ( $M$, visitante infantil da reserva- visita o local desde que nasceu acompanhada dos pais).

O ato de reconhecimento de um lugar por si só pressupõe a presença de quem o faz, com isso toda a bagagem cultural o acompanha em suas apreensões (SCHAMA, 1995). Considerando isto, e pensando em uma possível reaproximação do homem com o meio natural, é importante que em algum momento ao longo da visita o homem tenha um espaço de desconstrução de ideias e apertura para novas experiências. Nesse sentindo o Ritual do Lobo Guará mostra-se, a priori, uma oportunidade para isso:

A questão do lobo desperta a curiosidade, e faz pensar que tem que preservar, os pássaros não tem medo da gente, eles se aproximam, é diferente, a convivência, a pessoa entre no clima, aqui vê passarinho, vê lobo, as vezes se a pessoa tem alguma intenção de fazer alguma coisa contra a natureza ela reflete, é melhor o animal vivo, solto vivo, do que fechado ( $G$, historiador, visitante adulto da reserva, frequenta anualmente o local).

O Ritual do Lobo pode contribuir também, como evidencia o discurso acima, com a ideia de De Botton (2003), de que valores podem surgir a partir do contato com elementos naturais.

Outro aspecto importante ressaltado ao longo dos discursos foi a relação emotiva estabelecida entre os visitantes. O Caraça tem como característica a visitação anual de um público bastante fiel que acompanhou o processo do turismo no local. $O$ aspecto emocional é bastante ressaltado entre esse público, sendo apontado como uma das características que faz latente o desejo de sempre retornar à Reserva.

Me emociona também a parte humana daqui, a parte como os padres tratam os funcionários, as pessoas daqui. Os funcionários são muito compreendidos em suas necessidades. Nós tivemos alguns vínculos com alguns padres aqui, tivemos oportunidades de ter momentos mágicos daqui, inclusive com o Padre Tobias, o precursor desse contato com o lobo. Tanto com contato com o Lobo, tanto com relação assim com o interesse que ele tinha de divulgar a história desse local, isso ficou no meu imaginário como algo muito rico, me emociona, nós criamos amizades aqui $(R$, professora universitária, visitante adulta, frequentadora da Reserva a 18 anos).

As experiências no Caraça, como fora supracitado, são ditadas por um tempo e por costumes vinculados a religiosidade, proporcionando um distanciamento de ele- 
mentos que hoje acompanham todas as atividades urbanas como televisão, computador, celular. Ao realizar isso, gera-se um espaço de maior interação entre as pessoas que ali estão. Bruhns (2010:88) fala da passagem de um processo de "individualismo para o coletivismo, da racionalidade para a emocionalidade". Ainda segundo a autora, ocorre um sentimento de localismo e de identificação emocional, fruto dos relacionamentos, que embora não sejam de períodos muito longos são estruturados com muita intensidade, recordando aqui a aportação de Tuan (1983) ao ressaltar a importância da intensidade do contato para a qualidade do mesmo.

Muitas pessoas que vem não voltam porque não conseguem ficar tempo sem a tecnologia. Eu tento me desligar, aqui eu não sinto falta da tv, eu me sinto bem conversando com as pessoas, eu não tenho sites assim, tipo Orkut, facebook, eu só jogo, dai nem sinto tanta falta (M, visitante infantil da reserva- visita o local desde que nasceu acompanhada dos pais).

O discurso acima demonstra como o tempo e as experiências possibilitadas na Reserva podem gerar contatos mais diretos e emotivos entre os seus visitantes. Essas novas formas de sociabilidade se contrapõem as usualmente vivenciadas na sociedade atual - que costuma limitar e prescrever formas de relacionamentos - gerando vínculos de amizade entre as pessoas (Ortega, 2000).

Carvalho (1997) ao fazer referências ao movimento ecológico ressalta algumas de suas características como a contraposição deste aos valores de consumo instaurados na sociedade e a importância da subjetividade no resgate da relação entre a natureza e o homem. Em alguns discursos foi possível levantar reflexões críticas dos visitantes acerca do modelo hegemônico no qual estamos inseridos, tanto em relação à importância de uma sensibilização, como na gestão da própria unidade e também em relação ao entorno do Caraça que está muito impactado pela presença de empresas mineradoras:

Essa consciência é super importante. Mas infelizmente estamos num governo que não tá nem aí, um governo que preza a exportação, soja lá embaixo e minério aqui ( $T$, visitante anual do Caraça há 9 anos).

Eu acho que aqui tem pontos positivos, é dele estar nas mãos de uma organização de origem religiosa, a gente não tem a invasão do capitalismo (...) ( $R$, professora universitária, visitante adulta frequentadora da Reserva a 18 anos).

O entorno, tem área protegida, mas tem muita devastação, de uns 3 anos pra cá, a Vale, me causa muita tristeza, essa sensação de que eles tão destruindo tudo o que a gente tem aqui né (...)Esses minérios que vão pra China, pra outros países, nosso bem maior é a nossa tragédia também, que é o minério, que deu o nome pro nosso estado, vem devastando tudo, pela ganância (G, historiador, visitante adulto, frequenta o parque a 12 anos). 
Um aspecto relevante já apresentado pela bibliografia foi o esquecimento sofrido pelo bioma cerrado no imaginário da sociedade brasileira, gerado entre outros aspectos pela valorização unívoca de grandes florestas. Leff (2010) coloca que nossa percepção de mundo tem sido norteada pela racionalidade da modernidade. Neste processo, onde estão envolvidos conhecimento moderno e racionalidade econômica, tem-se uma globalização que unifica olhares e identidades de um mundo cuja principal característica é a diversidade. A falta de uma compreensão mais sensível da complexidade e também da valoração que circunda o cerrado pode ser observada em alguns discursos:

As pessoas tendem a valorizar mais as áreas que se percebe mais verde, tem algo inconsciente, se as pessoas tivessem que escolher 0 que preservar a mata atlântica ou cerrado, eu acho que as pessoas escolheriam a mata atlântica, porque tem mais densidade, achando que ali tem mais vida, tem mais vegetais, deve ter mais animais, os rios correm por ali e no cerrado elas pensariam o que, não tendo consciência que ali tem a sua diversidade, seus animais que preferem tá ali, que tem vida, é minha opinião ( $R$, professora universitária, visitante adulta, frequentadora da Reserva a 18 anos).

Percebe claramente que não é mais aquela Mata Atlântica tão poderosa né. Árvores maiores de mais tempo de vida, mais fechadas, aqui tem uma mata um pouco mais fechada, mas não chega a ser exuberante, aqui são espécies mais raquíticas, as árvores não crescem tanto ( $T$, professor de inglês, visitante anual do Caraça há 9 anos).

Ainda em relação a questões apontadas pela bibliografia, nos discursos também é possível levantar que o contato com a natureza através da viagem pode trazer o desejo de se preservar. Para Leff (2010) uma consciência ecológica generalizada e comum da espécie implica em que a humanidade comparta a vivencia de uma crise ambiental como uma catástrofe comum a toda coletividade, trazendo ao imaginário social um princípio simbólico.

(...) é um lugar especial, é diferente, você interage com a natureza, na cidade a gente não interage, não deveriam destruir esse lugar, essas mineradoras. Eu levo comigo esse lugar, mas assim as pessoas não conhecem aqui, então assim eu e os meus pais a gente leva pra nós assim as lembranças, o não querer deixar destruir aqui (M, visitante infantil da reserva- visita o local desde que nasceu acompanhada dos pais).

Não adianta ficar destacando que ta acabando. Por isso os ambientalistas estão ficando chatos, uma postura chata, bloqueia costumes tradicionais. O desenvolvimentismo está voltando. Não pode ser uma Educação Ambiental pelo medo, tem que ser pela vivência, sensibilização. É um sentir mesmo, não é racional (R, biólogo, já frequentou o parque 6 vezes).

Os discursos aqui apresentados apontam questões interessantes possibilitadas 
ao longo da experiência entre o ser humano e a natureza, em específico, o bioma Cerrado. O caso do Caraça é peculiar e mostra alternativas aos modelos de turismo de natureza existentes. A imbricação entre cultura, espiritualidade e natureza, presente no local, induz aos visitantes a questionamentos e vivências que se diferenciam do cotidiano opressor e limitante da vida urbana. Desta forma, o ecoturismo desenvolvido nesta unidade merece um estudo que compreenda as relações que se dão neste lugar, suas potencialidades e características.

\section{Conclusão}

O presente artigo buscou, através de uma revisão bibliográfica e da apresentação de resultados preliminares de uma pesquisa em desenvolvimento, revelar possíveis formas de estreitamento das relações entre o homem e o cerrado durante práticas de ecoturismo.

O estudo do ecoturismo sob o enfoque da percepção ambiental se faz necessário, uma vez que a informação derivada da experiência contribui para reflexões de planejamento da atividade. Pensar a viagem à natureza como uma aliada para se romper paradigmas da racionalidade moderna e se alcançar novas sensibilidades humanas em relação à natureza se faz importante no período crucial de crise enfrentado pela sociedade.

Nesse sentido, Irving (2008) afirma que para garantir a qualidade e a dinâmica do planejamento ecoturístico é necessário compreender tanto as subjetividades que envolvem o processo de entendimento do mundo de um turista de natureza como a interpretação de seus desejos. Corroborando com esta ideia Couto (2006) reconhece que uma pesquisa com o enfoque na percepção ambiental facilita a incorporação de ações que cooperem com as necessidades locais, uma vez que se compreendem as interpretações que um grupo tem de um lugar, assim como as relações que se estabelecem com o mesmo.

Como fora possível levantar através de alguns discursos, a RPPN "Santuário do Caraça" resguarda um turismo alternativo com denominadores que merecem ser investigados e analisados. Inicialmente nota-se que a questão emotiva, o tempo religioso e o encontro com o Lobo Guará são características que norteiam a experiência do visitante no local, provocando uma sensibilização no mesmo. Entretanto, com o desenvolver da presente investigação se objetiva compreender mais intensamente como se dão essas relações presentes e se, de fato, estas se fixam nos imaginários e se refletem em atitudes e hábitos, que possam contribuir para a preservação do bioma em questão.

\section{Referências bibliográficas}

BRUHNS, H.T. A ideia de natureza como fronteira. In: SERRANO, C.; BRUHNS, H.T; LUCHIARI, M.T.P. (Orgs) Patrimônio, natureza e cultura. Campinas, SP: Papirus, 2007.

BRUHNS, H.T. O corpo visitando a natureza: possibilidades de um diálogo crítico. In: SERRANO, C.T.; BRUHNS, H. T. (Orgs) Viagens à natureza: turismo, cultura e ambiente. 4. ed Campinas: Papirus, 1997. 
BRUHNS, H.T. O ecoturismo e o mito da natureza intocada. Acta Scientarum Human and Social Sciences, v. 32, p. 11-21, 2010.

BRUHNS, H.T.; MARINHO, A. Ritos e rituais nas viagens à natureza. Revista Brasileira de Ecoturismo, São Paulo, v.5, n.1, jan/abr-2012, pp.87-102.

CARVALHO, I.C.M. A tradição como horizonte de significação do ambiental. In: A invenção ecológica: narrativas e trajetórias da educação ambiental no Brasil. Ed: Universidaade/UFRGS: Porto Alegre, 2001.

CARVALHO, I.C.M. Os sentidos do ambiental: a contribuição da hermenêutica à pedagogia da complexidade. In: Enrique Leff. (Org.). A complexidade ambiental. 1 ed. São Paulo(SP), Blumenau(SC): Cortez e EDIFURB, 2003, v. , p. 99-120.

CARVALHO, I.C.M. As transformações na cultura e o debate ecológico: desafios políticos para a educação ambiental. In: PÁDUA, S.M.; TABANEZ, M.F. (Orgs). Educação Ambiental: caminhos trilhados no Brasil. Brasília: Ipê, 1997.

CASCINO, F. Pensando a relação entre educação ambiental e ecoturismo. In: SERRANO, C.M.T., BRUHNS, H.T.; LUCHIARI, M.T.D.P. Olhares contemporâneos sobre o turismo. Campinas: Papirus, 2000.

CONSERVAÇÃO INTERNACIONAL Brasil, Hotspots. Disponível em <http:// www.conservation.org.br/como/index.php?id=8> Acesso em: 22/09/2010.

COUTO, M.N.C. Percepção ambiental de grupos representativos da comunidade de Itaoca, São Gonçalo/RJ. 2006. 68f. Dissertação (Mestrado) - Universidade Federal Fluminense, Programa de Pós-Graduação em Ciência Ambiental. Disponível em: <http// www.uff.br/cienciaambiental/dissertações/MNCCouto.pdf> Acesso em 20/05/2012.

De BOTTON, A. A arte de viajar. Rio de Janeiro: Rocco, 2003.

DIEGUES, A.C. O mito moderno da natureza intocada. São Paulo: HUCITEC/ NUPAUB, USP, 2004 ( $5^{\circ}$ edição).

FARIA, M. O. O mundo globalizado e a questão ambiental. In: NEIMAN, Z. (Org). Meio Ambiente, educação e ecoturismo. Barueri: Manole, 2002.

FELFILI, J.M.; SILVA-S, J. C.; SCARIOT, A. Biodiversidade, ecologia e conservação do Cerrado: avanços no conhecimento. In: FELFILI, J.M.; SILVA-S, J. C.; SCARIOT, A. (Orgs) Cerrado, ecologia e conservação. MMA: Brasília, 2005.

FLICK, U. Introducción a la investigación cualitativa. Espanha: Ediciones Morata, 2002.

GEERTZ, C. A interpretação das culturas. Rio de Janeiro: Zahar, 1978.

GOODLAND, R.; FERRI, M. G. Ecologia do cerrado. São Paulo, Itatiaia/EDUSP, 1979.

GRUN, M. Ética e educação ambiental: a conexão necessária. São Paulo: Papirus, 1996.

GUIMARÃES, S. T. L. Reflexões a respeito da paisagem vivida, topofília e topofobia à luz dos estudos sobre experiência, percepção e interpretação ambiental. GEOSUL, Florianópolis, v. 17, n. 33, p. 117-141, 2002. 
Frederico, I.B.; Bruhns, H.T.

IRVING, M. A. Ecoturismo em áreas naturais: da natureza ao fenômeno social. In: COSTA, N.M.C.; NEIMAN, Z.; COSTA, V.C. Pelas trilhas do ecoturismo. Rima: São Carlos, 2008.

KLINK, C. A.; MACHADO, R.B. A conservação do Cerrado brasileiro. Megadiversidade, v.1, p.147 - 155, 2005.

LEFF, E. Imaginarios sociales y sustentabilidad. In: Cultura y Representaciones Sociales, 2010. Vol.5.No.9. Disponible en http://132.247.146.34/index.php/crs/article/ view/19202.. Acesso em 10/05/2012.

LEIS, H. Espiritualidade e Globalização na perspectiva do ambientalismo. Ambiente e Sociedade, ano 1, n.2, 1 semestre 1998.

MACHADO, R.B., RAMOS-NET, M.B.; PEREIRA, P.G.P.; CALDAS, E.F.; GONÇAÇVES. D.A.; SANTOS, N.S.; TABOR, K.; STEININGER, M. Estimativas de perda da área do Cerrado brasileiro. Conservation International do Brasil, Brasília: 2004.

MAMEDE, S. B.; BENITES, M. Contemplação da fauna no cerrado brasileiro: uso sustentável para o ecoturismo. In: COSTA, N.M.C.; NEIMAN, Z.; COSTA, V.C. Pelas trilhas do ecoturismo. Rima: São Carlos, 2008.

MARIN, A. A. ; OLIVEIRA, H. T.; COMAR, M. V. Percepção ambiental, imaginário e práticas educativas. Textos completos do III Encontro de Pesquisa em Educação Ambiental, Ribeirão Preto, versão em CD-Room, 2005.

MMA (Ministério do Meio Ambiente). Ações prioritárias para a conservação da biodiversidade do Cerrado e do Pantanal. Brasília: MMA, 2007.

NEIMAN, Z; RABINOVICI, A. O cerrado como instrumento para educação ambiental em atividades de ecoturismo. In: NEIMAN, Z. (Org.). Meio ambiente, educação e ecoturismo. Barueri: Manole, 2002.

ORTEGA, F. Para uma política da amizade: Arendt, Derrida, Focault, 2. Ed. Riode de Janeiro: Relume Dumará, 2000.

PEREIRA, D.C.; CARRIERI, A.P. Espaço religioso e espaço turístico: significações culturais e ambiguidades no Santuário do Caraça/MG. O\&S. Salvador, v. 12, n. 34, p. 31-50, 2005.

PIRES, P.S. A dimensão conceitual do ecoturismo. Turismo - Visão e Ação - v.1 - n.1, p.75-91, 1998.

REIGOTA, M. Meio ambiente e representação social. São Paulo: Cortez, 2000.

RODRIGUES, M.T. A biodiversidade do cerrado: conhecimento atual e perspectivas, com uma hipótese sobre o papel das matas galerias na troca faunística durante ciclos climáticos. In: FELFILI, J.M.; SOUZA-SILVA, J.C.; SCARIOT, A. (Orgs) Cerrado, ecologia e conservação. MMA: Brasília, 2005.

SCHAMA, S. Paisagem e memória. São Paulo, Companhia das Letras, 1995.

SEGALEN, M. Ritos e rituais contemporâneos. Rio de Janeiro. FGV: 2002.

SELLTIZ, C. Métodos de pesquisa nas relações sociais. São Paulo: E.P.U.: USP, 1995. 
THOREAU, H.D. Walden ou a vida nos bosques. São Paulo: Aquariana, 2001.

TUAN, Yi-Fu (autor). Espaço e lugar: a perspectiva da experiência. São Paulo: DIFEL, 1983.

WESTERN, D. Como definir o ecoturismo. In: LINDBERG, K; HAWKINS, D. E. (Orgs) Ecoturismo: um guia para planejamento e gestão. São Paulo: Senac, 2005 ( $5^{\circ}$ edição).

WWF- BRASIL. Expansão Agrícola e a perda da biodiversidade no Cerrado: origens históricas e o papel do comércio internacional. Brasília, 2000.

\section{Agradecimentos}

Em especial, à Coordenação de Aperfeiçoamento e Coordenação de Pessoal de Nível Superior - CAPES que está apoiando financeiramente a realização desta pesquisa de mestrado; e a Coordenação Ambiental da RPPN "Serra do Caraça" por estar colaborando com toda a infraestrutura e abertura necessária para o desenvolvimento do presente estudo.

Isabela Barbosa Frederico: Universidade Estadual de Campinas, Campinas, SP, Brasil.

Email: isabf_tur@yahoo.com.br

Link para o currículo Lattes: http://lattes.cnpq.br/5797747004349745

Heloisa Turini Bruhns: Universidade Estadual de Campinas, Campinas, SP, Brasil.

Email: luabola@uol.com.br

Link para o currículo Lattes: http://lattes.cnpq.br/6033060712348685

Data de submissão: 30 de junho de 2012

Data de recebimento de correções: 17 de agosto de 2012

Data do aceite: 17 de agosto de 2012

Avaliado anonimamente 